\title{
Influence of protein and hormone supplementation on in vitro maturation and fertilization of domestic cat eggs
}

\author{
T. C. Wood ${ }^{1,2}$, A. P. Byers ${ }^{1}$, B. E. Jennette ${ }^{1}$ and D. E. Wildt ${ }^{1,2}$ \\ ${ }^{\mathrm{T}}$ National Zoological Park, Conservation and Research Center, Smithsonian Institution. Washington, \\ DC 20008 and Front Royal, VA 22630, USA; and ${ }^{2}$ George Mason University, Department of Biology, \\ Fairfax, VA 22030, USA
}

Immature eggs were recovered from freshly excised ovaries from domestic cats, and initially 931 eggs with a compact cumulus and uniform cytoplasm were cultured in 1 of 15 treatments. Eagle's minimum essential medium containing glutamine and pyruvate was supplemented with $5 \%(\mathrm{v} / \mathrm{v})$ fetal calf serum (FCS), $4 \mathrm{mg}$ bovine serum albumin (BSA) $\mathrm{ml}^{-1}$ or $2 \mathrm{mg}$ polyvinyl alcohol $\mathrm{ml}^{-1}$ (PVA; non-protein control). Within each of these supplement groups, eggs were cultured with: no hormone; $\mathrm{LH}+\mathrm{FSH} ; \mathrm{LH}+\mathrm{FSH}+$ oestradiol; or $\mathrm{LH}+\mathrm{FSH}+$ oestradiol + progesterone. After incubation for $52 \mathrm{~h}$, eggs were inseminated with conspecific fresh spermatozoa, cultured and examined for stage of meiotic maturation and in vitro fertilization (IVF). There were fewer $(P<0.05)$ eggs maturing to metaphase II in vitro in FCS compared with BSA or PVA, the last two treatments producing similar $(P<0.05)$ results. Gonadotrophins in concert with oestradiol or oestradiol + progesterone improved the incidence of maturation $(P \leq 0.01)$ compared with no added hormones. The incidence of fertilization and cleavage in vitro ranged from 5.2 to $33.9 \%$ and varied $(P<0.05)$ with hormone subtreatment. Adding FSH $+\mathrm{LH}+$ oestradiol consistently increased the incidence of IVF approximately twofold compared with controls with no added hormones. Although it inhibited the ability of eggs to reach metaphase II, FCS in the presence of gonadotrophins and oestradiol allowed $>60 \%$ of mature eggs to fertilize in vitro $(P<0.05$, compared with PVA and BSA). Inhibitory effects on egg maturation were further evaluated by testing four FCS batches from three commercial sources against BSA. All FCS batches were clearly inhibitory, as $60.7 \%$ of treated eggs arrested at the germinal vesicle stage (21.1\% of BSA-treated eggs, $P<0.001$ ). Dialysis of FCS eliminated a significant proportion of the inhibition; 69 of 158 eggs $(43.7 \%)$ matured compared with 22 of 135 $(16.3 \%)$ in complete or 23 of $160(14.4 \%)$ in recombined serum. In summary, FCS appears to exert a paradoxical effect in this system, inhibiting maturation in vitro (apparently due to small molecular weight components), but promoting IVF of mature eggs if gonadotrophins and oestradiol are present. Although hormone supplementation enhanced the ability of in vitro matured eggs to fertilize and cleave, neither protein source nor the hormone treatments tested here appear responsible for the consistently low incidence of fertilization in cat eggs matured in vitro.

\section{Introduction}

Developing reliable in vitro egg maturation (IVM) and fertilization (IVF) techniques in the domestic cat may eventually allow the rescue of haploid genetic material from endangered felid species that unexpectedly die. This technology could be important in conservation biology because of its potential for salvaging genes from non-domestic felids underrepresented in captive populations (Wildt, 1990). Because one of the longterm goals of species conservation is to maintain all existing gene diversity, especially in small and insular populations,

Revised manuscript received 27 April 1995. extraordinary efforts, like IVM and IVF, may be necessary to preserve genetic health or even entire species. In addition to having considerable practical potential, these techniques are valuable tools for understanding the basic mechanisms associated with gamete development, interaction and early stage preimplantation embryo development. Compared with laboratory rodents and livestock species, there is a surprising lack of information on these phenomena in carnivores.

Studies in domestic cats have (i) established the time-course of egg maturation in vitro (Goodrowe et al., 1991) and in vivo (Byers et al., 1994) and (ii) demonstrated that eggs matured in vitro are also capable of fertilizing in vitro (Johnston et al. 1989). IVM/IVF techniques developed in domestic cats have 
also been adapted to 13 wild felid species (Johnston et al, 1991a). Although success is highly variable and generally less than in domestic cats, the proportion of cultured eggs achieving nuclear maturation approaches that of cats (about 50\%) in some species like the puma (Felis concolor), snow leopard (Panthera uncia) and serval (Felis serval).

These results are encouraging, but similar studies in other species, especially mice (Schroeder and Eppig, 1984), rats (Vanderhyden and Armstrong, 1989), cows (Leibfried-Rutledge et al., 1986, 1987; Sirard et al., 1988; Brackett et al., 1989; Fukui and Ono, 1989) and pigs (Ocampo et al., 1993), indicate that it is possible to achieve considerably higher IVM and IVF rates than are presently observed in domestic cats. No doubt some of these differences are due to species specificities (Schultz, 1991). However, it should be possible to improve the efficiency of oocyte rescue in cats to that at present achieved in other species. Therefore, the aim of this study was to identify systematically various culture factors that influence maturation and fertilizability in vitro of cat eggs.

The impact of protein and hormone supplementation on IVM and IVF of cat ovarian oocytes was analysed. The use of serum as a general protein source for egg culture was studied in mice (Downs et al., 1986), rats (Vanderhyden and Armstrong, 1989) and cows (Fukui and Ono, 1989; Younis et al., 1989; Sanbuissho and Threlfall, 1990; Zuelke and Brackett, 1990; Saeki et al., 1991). Serum prevents zona hardening of cultured mouse embryos, a process marked by slower (i) $\alpha$-chymotrypsin dissolution of the zona pellucida and (ii) modification of ZP2 (a glycoprotein sperm receptor) to ZP2f (a form that inhibits polyspermy) (Schroeder et al., 1990; Eppig, 1991). The consensus view of the few species studied is that the presence of supplemental protein in the form of serum is beneficial for IVF and early embryo development, but controversy remains concerning its importance for in vitro egg maturation (Thibault et al., 1987; Downs, 1993).

There are also conflicting results on the role of gonadotrophins and steroids as IVM/IVF supplements in mammals, especially in bovine studies (Moor et al., 1980; Sirard et al., 1988; Fukui and Ono, 1989; Younis et al., 1989; Sanbuissho and Threlfall, 1990). Saeki et al. (1991) reported that bovine eggs can be matured in vitro without serum and co-cultured with spermatozoa in the presence or absence of hormones (gonadotrophins and oestradiol). Nuclear maturation is unaffected, but both fertilization and development in vitro are enhanced by hormones. These findings demonstrate the potential value of exogenous gonadotrophins and oestrogen for egg culture. Progesterone appears to stimulate the interaction between the egg and its cumulus cell complement in the pig wher supplemented at concentrations found in follicular fluid (Mattioli et al., 1988). Progesterone also exerts a beneficial effect upon IVM/ IVF of unprimed rat (Zhang and Armstrong, 1989) and bovine (Karlach, 1987) eggs.

The aim of this study was to evaluate the impact of the presence or absence of protein and various combinations of gonadotrophins and steroid hormones upon IVM and IVF of immature domestic cat eggs and to elucidate further the basic requirements for egg development and sperm-egg interaction in this species, to determine whether the absolute requirements for egg maturation mimicked those needed to achieve fertilization in vitro.

\section{Materials and Methods}

\section{Collection of cumulus-egg complexes}

Domestic cat ovaries were collected from ovariohysterectomy material provided by local veterinary clinics. Immediately upon excision, ovaries were placed into $50 \mathrm{ml}$ centrifuge tubes (Corning Glass Works, Corning, NY) containing $15 \mathrm{ml}$ Dulbecco's phosphate-buffered saline (DPBS), 100 iu penicillin $\mathrm{ml}^{-1}, 30$ iu streptomycin $\mathrm{ml}^{-1}$ and $0.2 \mathrm{mg}$ neomycin $\mathrm{ml}^{-1}$ (Sigma Chemical Co., St Louis, MO) and stored at room $\left(22^{\circ} \mathrm{C}\right.$ ) temperature. Eggs were harvested from antral ovarian follicles within $4 \mathrm{~h}$ of ovariohysterectomy using a scalpel blade to longitudinally bisect each ovary. The ovarian cortical region was repeatedly sliced, and released eggs were placed into $60 \mathrm{~mm}$ tissue culture dishes (Corning Glass Works) containing pre-equilibrated $\left(38^{\circ} \mathrm{C}, 5 \% \mathrm{CO}_{2}\right.$ in air) culture medium.

\section{Culture treatments and egg selectionlevaluation for maturation}

Only eggs with compact cumulus oophorus/corona radiata complements and a uniform, dark cytoplasm were used (Goodrowe et al., 1988; Johnston et al., 1989). All in vitro egg culture was conducted in Eagle's minimum essential medium (Sigma) supplemented with 30 iu streptomycin $\mathrm{ml}^{-1}, 120 \mathrm{iu}$ penicillin $\mathrm{ml}^{-1}$ (Gibco Laboratories, Grand Island, NY), $0.026 \mathrm{~g}$ pyruvate $\mathrm{I}^{-1}$ and $0.292 \mathrm{~g}$ L-glutamine $\mathrm{I}^{-1}$ (Sigma), hereafter referred to as MEM. Eggs were matured in $35 \mathrm{~mm}$ tissue culture dishes (Corning Glass Works) in groups of 5-15 eggs per $100 \mu \mathrm{l}$ drop under mineral oil (Mallinckrodt Inc., Paris, KY). All cultures were conducted in a $38^{\circ} \mathrm{C}$ humidified incubator containing $5 \% \mathrm{CO}_{2}$ in air.

The influence of protein and hormone supplementation on egg maturation and subsequent fertilization was investigated by designing a $3 \times 5$ factorial experiment (three protein treatments $\times$ five hormone subtreatments). Protein treatments consisted of $4 \mathrm{mg} \mathrm{BSA} \mathrm{ml}^{-1}$ (Sigma A-4161 lot 118F-9301-5), $5 \%(\mathrm{v} / \mathrm{v})$ FCS (HyClone Laboratories, Logan, UT) or $2 \mathrm{mg}$ polyvinyl alcohol $\mathrm{ml}^{-1}$ (PVA, a non-protein control; Sigma). The hormones and dosages tested included: $10 \mu \mathrm{g}$ ovine $\mathrm{LH}$ $\mathrm{ml}^{-1}$ (NIADDK-oLH-25; National Hormone and Pituitary Program, Rockville, MD); $1 \mu \mathrm{g}$ ovine FSH $\mathrm{ml}^{-1}$ (NIADDKoFSH-17; National Hormone and Pituitary Program); $1 \mu \mathrm{g}$ oestradiol $\mathrm{ml}^{-1}$ (Sigma); and I $\mu \mathrm{g}$ progesterone $\mathrm{ml}^{-1}$ (Steraloids Inc., Wilton, NH). Within each protein treatment group, five hormone subtreatments were tested: (i) no hormones; (ii) $\mathrm{LH}+\mathrm{FSH}$; (iii) $\mathrm{LH}+\mathrm{FSH}+$ oestradiol; (iv) $\mathrm{LH}+\mathrm{FSH}+$ progesterone; and (v) $\mathrm{LH}+\mathrm{FSH}+$ oestradiol + progesterone ( $n=52$ or more eggs per subgroup).

On any given collection day, eggs were distributed randomly among 3-5 subtreatments and cultured for $52 \mathrm{~h}$ (as above), and then removed from the incubator and co-cultured with a conspecific sperm cell suspension. Subgroups were rotated daily to minimize any seasonal impact on the quality of eggs collected. After $36 \mathrm{~h}$, cumulus cells were removed from all eggs with a small bore pipette. Non-cleaved eggs were evaluated for degree of nuclear meiotic maturation by fixing with $0.3 \%(\mathrm{w} / \mathrm{v})$ glutaraldehyde (Sigma) in DPBS for $10 \mathrm{~min}$ and staining with $0.5 \mathrm{mg} \mathrm{4,6}$ diamidino-2-phenylindole $\mathrm{ml}^{-1}$ (DAPI; Sigma) for $10 \mathrm{~min}$. Chromosomes were evaluated under 
fluorescence excitation on a flat slide at $\times 400$ magnification using a Leitz Diaplan microscope (Wetzlar). Each egg was placed onto a clean microscope slide in a 3-5 $\mu$ drop of DPBS and covered with a $22 \mathrm{~mm}^{2}$ coverslip. A small amount of a petroleum jelly:paraffin wax mixture (1:1) was applied to each coverslip edge to raise the coverslip slightly. With the aid of a stereomicroscope (Nikon Inc., Garden City, NY; Model SMZ2T; $\times 30$ magnification), each coverslip was pressed gently to flatten, but not rupture, the eggs. Any egg with a germinal vesicle or exhibiting germinal vesicle breakdown, meiosis I or evidence of degeneration was classified as immature, whereas those reaching telophase of meiosis I or metaphase of meiosis II were classified as mature (Johnston et al., 1989).

\section{Semen collection and in vitro fertilization}

Cats used for semen collection were housed in individual $4.75 \mathrm{~m}^{3}$ wards, maintained under a photoperiod of $12 \mathrm{~h}$ light: $12 \mathrm{~h}$ dark and provided Science Diet Feline Maintenance Light cat food (Hill's Pet Nutrition Inc., Topeka, KS) and water ad libitum. Spermatozoa for IVF were collected using an artificial vagina in a slight modification of the procedure described by Sojka et al. (1970). Ejaculates were processed using a swim-up procedure (Goodrowe et al, 1988) immediately into Ham's F10 medium (Irvine Scientific, Santa Ana, CA) supplemented with 30 iu streptomycin $\mathrm{ml}^{-1}, 120$ iu penicillin

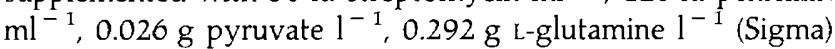
and $5 \%(\mathrm{v} / \mathrm{v})$ FCS (HyClone), hereafter referred to as Ham's F10. This process involved centrifugation of diluted semen (1:I, semen/Ham's F10) in a $1.5 \mathrm{ml}$ conical tube (Sarstedt Inc., Princeton, NJ) at $80 \mathrm{~g}$ for $8 \mathrm{~min}$ in an Eppendorf $5415 \mathrm{C}$ centrifuge (Brinkman Instruments, Westbury, NY). The supernatant was aspirated; $100 \mu \mathrm{l}$ fresh Ham's F10 was layered carefully onto the pellet; and the spermatozoa allowed to swim up for $1 \mathrm{~h}\left(22^{\circ} \mathrm{C}\right)$. Sperm concentration was measured using a haemocytometer, and a subjective assessment was made of percentage motility and progressive status of spermatozoa $(0=$ no sperm movement to $5=$ rapid, linear forward progression; Howard et al. 1986). All inseminates expressing a swim-up sperm rating of at least $75 \%$ motility and 3.0 progressive status were diluted in Ham's F10 to a final concentration of $2 \times 10^{5}$ motile sperm cells $\mathrm{ml}^{-1}$

After $52 \mathrm{~h}$ of maturation culture (Johnston et al., 1989), 5-15 eggs were co-cultured together with a total of $2 \times 10^{4}$ motile spermatozoa in a $100 \mu \mathrm{l}$ drop in Ham's F10 under mineral oil. As a control for parthenogenetic cleavage, 129 eggs were selected randomly throughout the study (from each of the 15 subtreatment groups) and cultured in IVF medium without spermatozoa. After 12-18 h, cumulus cells were removed by gently pipetting eggs through a finely-drawn glass pipette. Denuded eggs were returned to fresh $50 \mu \mathrm{l}$ drops of Ham's F10 under oil to continue culture for $36 \mathrm{~h}$ before being evaluated for cleavage. After $36 \mathrm{~h}$, eggs and embryos were fixed with glutaraldehyde and stained with DAPI to confirm maturation, fertilization and embryo cleavage. Evidence for presumptive fertilization included the presence of two pronuclei or two polar bodies or embryo cleavage as described in detail by Goodrowe et al. (1988).
Further evaluation of fetal calf serum and oestradiol on meiotic maturation

Initial trials revealed a significant inhibitory impact of FCS and an enhancement effect of oestradiol on maturation of cat eggs in vitro. These phenomena were confirmed and explored further by conducting two additional trials, the first analysing both the influence of the FCS source and the FCS constituents on egg meiosis. Four randomly selected lots of FCS, obtained from three commercial suppliers (two lots from HyClone, characterized FCS lots 11152381 and 11152413, hereafter referred to as 'SI' and 'S2', respectively; one lot from Sigma Chemical Co., F-2442 lot 34H0894, referred to as 'S3'; and one lot from Irvine Scientific, lot 300021206, referred to as 'S4') were used to culture 275 additional eggs. These sera were added to the original culture medium (described above) in the same concentration (5\%) and supplemented with $\mathrm{LH}+$ $\mathrm{FSH}+$ oestradiol (same concentrations as described earlier). The comparative control was the culture medium containing the same hormones, but BSA (same lot and concentration; $n=71$ ) rather than FCS. All other culture factors were held constant except that all eggs were evaluated at 24 rather than $48 \mathrm{~h}$ of culture.

One of these sera (S3) was selected randomiy for dialysis to remove serum components smaller than $1 \mathrm{kDa}$ (Cellu.Sep HI; Membrane Filtration Products Inc., San Antonio, TX). Two millilitres of serum were dialysed with 31 of water over a period of $72 \mathrm{~h}$ and five water changes. The dialysed fraction was lyophilized, resuspended in $2 \mathrm{ml}$ MEM and stored in frozen aliquots. Eggs were cultured in standard conditions with $\mathrm{LH}+\mathrm{FSH}+$ oestradiol supplementation plus $5 \%(\mathrm{v} / \mathrm{v})$ complete serum (S3) ( $n=135$ eggs), $5 \%(v / v)$ dialysed serum ( $n=158)$ or $5 \%(\mathrm{v} / \mathrm{v})$ recombined serum (dialysed + lyophilized fractions) $(n=160)$ for $24 \mathrm{~h}$ before maturation assessment.

In the second trial that analysed further the positive influence of oestradiol, routinely collected cat eggs were cultured in BSA-supplemented MEM (4 $\mathrm{mg} \mathrm{ml}^{-1}$ ) containing: (i) $\mathrm{LH} \mathrm{+}$ FSH only ( $n=100)$; (ii) LH + FSH + oestradiol $(n=100)$; or (iii) oestradiol alone $(n=96)$ in similar hormone concentrations to that described in the original experiment. Eggs were evaluated for meiotic status after $24 \mathrm{~h}$ of culture.

\section{Statistical analyses}

A general loglinear analysis was performed on the factorial design for three protein and five hormone treatments for eggs matured, fertilized and cleaved. Bonferroni $t$ tests (Dunn, 1961) between loglinear parameters for protein and hormone effects were performed when the interaction was insignificant $(P \geq 0.05)$.

The loglinear model on the $3 \times 5$ factorial design for maturation revealed no interaction $(P=0.31)$, and multiple comparisons within protein and hormone treatments were performed. Multiple comparisons were performed for the percentage of eggs cultured that fertilized $(P=0.05)$ and for the percentage of eggs cultured that cleaved $(P=0.09)$. There was a significant interaction $(P=0.03)$ between protein and hormones when evaluating fertilization conditional on maturation. A discussion of the sources of this interaction is presented. 
Table 1. Numbers and percentages of domestic cat eggs that matured, fertilized and cleaved during in vitro culture

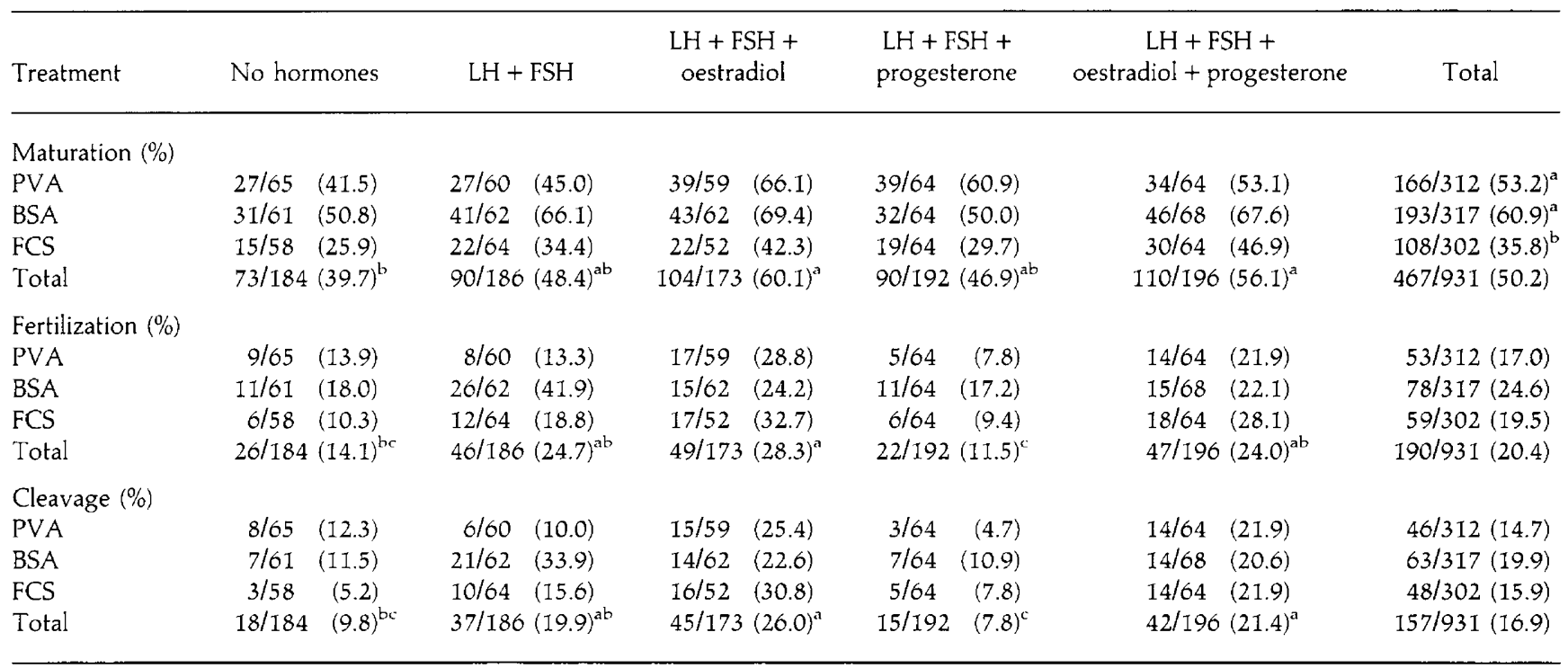

All eggs selected for maturation were subjected to insemination in vitro. Within the 'Maturation', 'Fertilization' and 'Cleavage' subtables 'total' numbers with different superscripts are significantly different $(P<0.05)$.

The additional maturation trials, evaluating the FCS inhibition of meiosis and oestradiol enhancement of maturation, were evaluated by chi-squared analysis with a Yates correction.

\section{Results}

Egg maturation in the $3 \times 5$ factorial experiment

In the factorial experiment containing 15 subtreatments, 467 of $931(50.2 \%)$ cultured eggs matured (Table 1), similar to a mean range of $46-48 \%$ nuclear maturation reported by others working with this species (Johnston et al., 1989, 1993; Goodrowe et al., 1991). Seventy-three of 184 eggs (39.7\%) achieved nuclear maturation in the absence of any direct gonadotrophin or steroid hormone supplementation. Twentyseven of $65(41.5 \%)$ eggs exposed only to PVA and no exogenous hormones also matured in vitro. Disregarding the potential impact of hormonal supplements, BSA (193 of 317. $60.9 \%$ ) provided the highest incidence of maturation, which was not different $(P>0.05)$ from the non-protein control, PVA (166 of 312,53.2\%). Both BSA and PVA provided superior maturation to FCS (108 of 302, 35.8\%; $P<0.001$ ). The lowest incidence of maturation occurred using FCS in each of the five hormone treatments. In contrast, and with the exception of $\mathrm{LH}+\mathrm{FSH}+$ progesterone, BSA provided the highest incidence of maturation. Gross examination of eggs indicated that cumulus expansion and mucification were most prominent in the FCS-treated groups, with BSA providing intermediate amounts and PVA a low amount of expansion with virtually no mucification. There was readily apparent cumulus cell expansion in all groups of eggs receiving some type of hormone treatment.

With respect to hormone supplements, and disregarding the potential impact of protein, the combined gonadotrophins
(FSH $+\mathrm{LH})$ alone increased maturation by $8.7 \%$ compared with the no hormone controls (Table 1), but the difference was not significant $(P>0.05)$. Adding oestradiol to the gonadotrophins, regardless of the presence of progesterone, increased the incidence of maturation $(P \leq 0.01)$ compared with controls with no added hormones; this observation was reconfirmed in a subsequent trial (see below). Adding progesterone with gonadotrophins did not produce a different effect from that of gonadotrophins alone or in the absence of all hormones $(P>0.05)$. Overall, the highest incidence of maturation $(60.1 \%)$ occurred in the presence of $\mathrm{FSH}+\mathrm{LH}+$ oestradiol.

\section{Fertilization and cleavage of eggs}

Of 129 eggs cultured without spermatozoa, five cleaved (a $3.9 \%$ incidence of parthenogenesis). Overall, 190 of 931 $(20.4 \%)$ of cultured/inseminated eggs fertilized (based upon formation of a male pronucleus or cleavage). Type or presence of supplemental protein had no effect on fertilization (range, $17.0 \%$ for PVA to $24.6 \%$ for BSA; Table 1). The highest rate of fertilization occurred in the subtreatments that provided gonadotrophins only or gonadotrophins supplemented with oestradiol or oestradiol + progesterone. In the absence of oestradiol, gonadotrophins + progesterone resulted in low fertilization equal $(P>0.05)$ to that of the no hormone control (Table 1$)$. Nevertheless, even in the absence of all exogenous hormones, $14.1 \%$ of cultured and inseminated eggs fertilized.

The effect of treatment was examined more closely, by analysing fertilization data on the basis of eggs matured at the time of insemination. Although inhibitory to maturation, FCS had no further detrimental effect upon fertilization. On the contrary, when eggs failing to mature were excluded and IVF success examined, more than $60 \%$ of eggs exposed to FCS in $\mathrm{LH}+\mathrm{FSH}+$ oestradiol or $\mathrm{LH}+\mathrm{FSH}+$ oestradiol + 


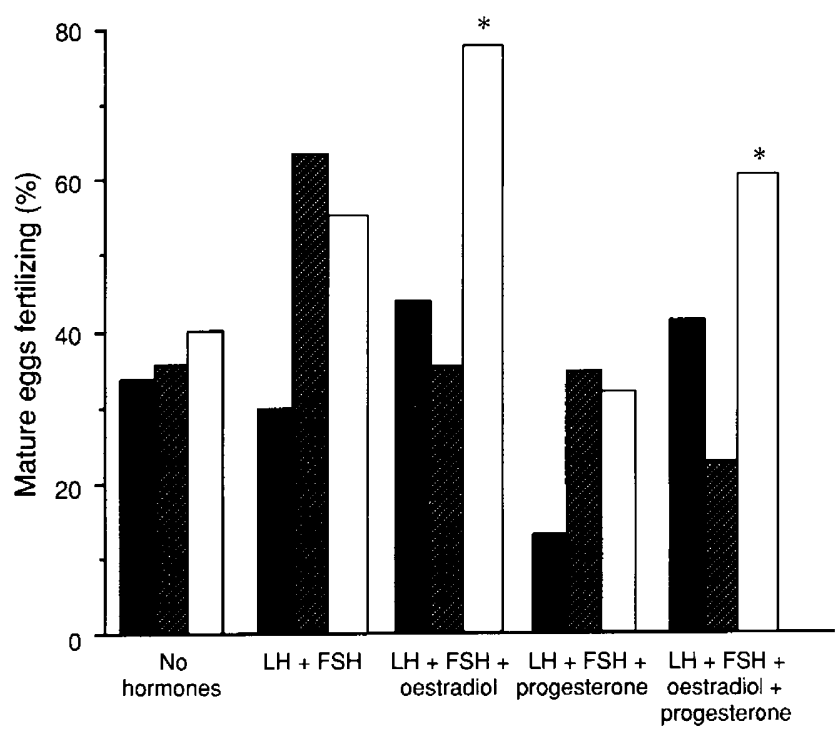

Fig. 1. Percentage of domestic cat eggs fertilizing after maturation in one of three protein supplements ( $\boldsymbol{\square}$, polyvinyl alcohol PVA, control; BSA; $\square$, fetal caif serum FCS) and one of five hormone treatments (no hormones; $\mathrm{LH}+\mathrm{FSH} ; \quad \mathrm{LH}+\mathrm{FSH}+$ oestradiol; $\mathrm{LH}+\mathrm{FSH}+$ progesterone; $\mathrm{LH}+\mathrm{FSH}+$ oestradiol + progesterone). *An overall interaction between protein and hormone supplements was promoted by the two FCS groups containing gonadotrophins plus oestradiol.

progesterone fertilized (Fig. 1). When fertilization was evaluated in the context of maturation, there was a significant $(P=0.03)$ interaction between protein source and hormone treatment, the cause being the promotional effect of gonadotrophins in the presence of oestradiol or oestradiol+ progesterone and FCS (Fig. 1).

Most fertilized eggs $(n=190)$ cleaved $(n=157 ; 82.6 \%)$. However, few total cultured eggs cleaved (5.2-33.9\%; Table 1). On the basis of the total number of eggs, there were no differences $(P>0.05)$ in the ability of either protein treatment (BSA or FCS) to produce more embryos than did the control, PVA (Table 1). However, among hormone subtreatment groups, embryo production was always increased by $2-3$ times $(P<0.05)$ when $\mathrm{LH}+\mathrm{FSH}+$ oestradiol or $\mathrm{LH}+\mathrm{FSH}+$ oestradiol + progesterone were added to the maturation medium compared with no added hormones or $\mathrm{LH}+$ $\mathrm{FSH}+$ progesterone (Table 1).

Further evaluation of fetal calf serum and oestradiol on meiotic maturation

More than half $(167$ of $275,60.7 \%)$ of all eggs cultured in $5 \%(\mathrm{v} / \mathrm{v})$ FCS were arrested in the germinal vesicle stage compared with only $21.1 \%$ (15 of 71 ) of eggs cultured in BSA $(P<0.001)$ (Fig. 2). A low percentage of eggs cultured in the FCS groups and BSA was degenerate $(8.4-16.9 \%)$ or in metaphase I (11.3-17.2\%) $(P>0.05)$ (Fig. 2). However, the majority of eggs in the BSA group were at metaphase II $(59.2 \%)$, in contrast to only $7.7-17.4 \%$ of all FCS-treated eggs $(P<0.001)$, thus reconfirming the inhibitory influence of BSA on cat egg meiotic maturation.

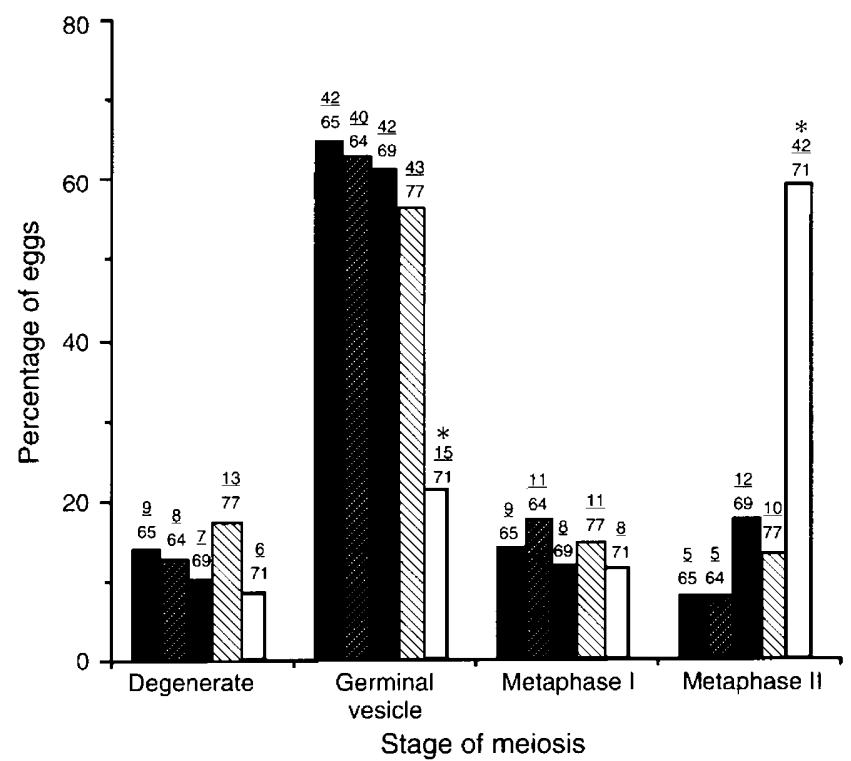

Fig. 2. Inhibition of meiotic maturation of domestic cat eggs cultured in four randomly selected batches of fetal calf serum (FCS) versus BSA

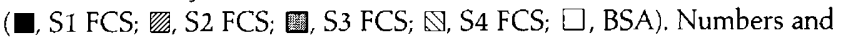
proportions of eggs are indicated at the top of each bar. Columns with asterisks within stages of meiosis are significantly different $(P<0.001)$.

In comparing the effect of complete, dialysed and recombined FCS, few eggs exposed to any of these treatments were found to be degenerate (overall, 20 of $453,4.4 \%$ ) or in meiosis I $(31$ of $453,6.8 \%$ ) (no difference among individual treatments, $P>0.05$ ) (Fig. 3). However, complete FCS and recombined FCS fractions clearly inhibited meiosis in the germinal vesicle stage ( 214 of $295,72.5 \%)$, whereas dialysing to remove smaller molecules $(<1 \mathrm{kDa})$ partially eliminated this inhibition (74 of $158,46.8 \% ; P<0.001)$. In addition, more $(P<0.001)$ eggs cultured in the dialysed fraction matured to metaphase II (69 of $158,43.7 \%$ ) than in complete ( 22 of $135,16.3 \%$ ) or recombined FCS (23 of $160,14.4 \%$ ) fractions.

With respect to the impact of oestradiol, few eggs treated with $\mathrm{LH}+\mathrm{FSH}, \quad \mathrm{LH}+\mathrm{FSH}+$ oestradiol or oestradiol alone were degenerate ( 12 of $296,4.1 \%$ ), in the germinal vesicle stage (67 of 296, 22.6\%) or in meiosis I (51 of 296, 17.2\%; Fig. 4). Most eggs matured to meiosis II (166 of 296, 56.1\%), and there were no differences $(P>0.05)$ among hormone supplement groups within any stage of maturation observed (Fig. 4).

\section{Discussion}

Four important and fundamental observations were made in this study. First, protein supplementation was not required for cat egg maturation and subsequent fertilization in vitro. Nuclear maturation occurred spontaneously in some eggs isolated from antral follicles and cultured in vitro without extra protein beyond that available in the standard culture medium. Second, meiotic nuclear maturation was clearly inhibited in the germinal vesicle stage when antral oocytes were cultured in the presence of FCS for 24 or $52 \mathrm{~h}$. Third, exogenous hormones 


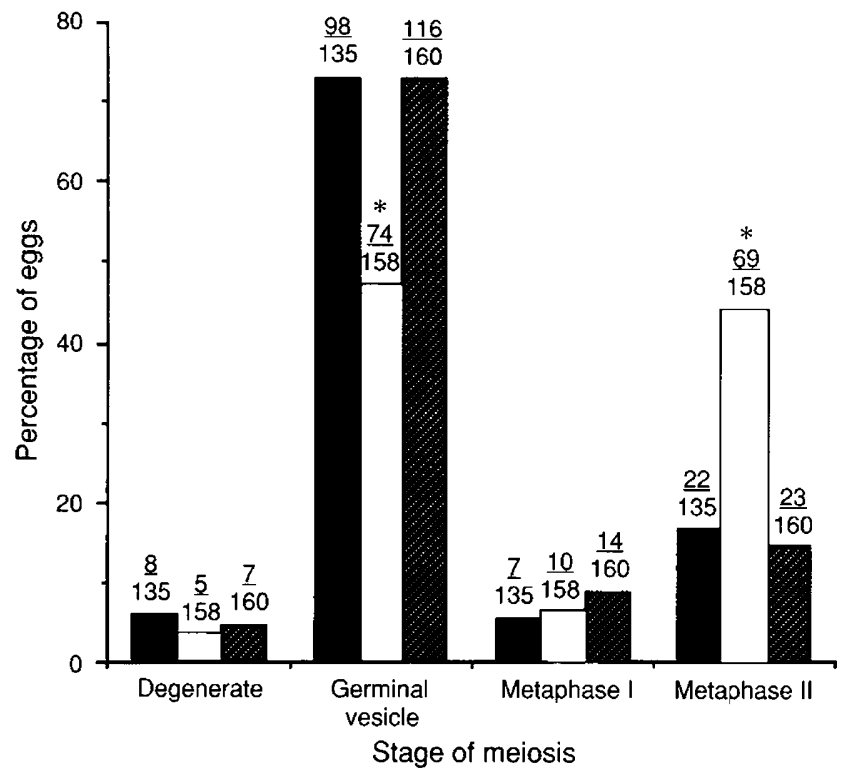

Fig. 3. Inhibition of meiotic maturation by ( $\mathbf{0}$ ) fetal calf serum FCS; (D) partial removal of the inhibition by dialysing molecules smaller than $1 \mathrm{kDa}$; and $(\mathbb{Z})$ re-inhibition by recombining the dialysed FCS fractions. Numbers and proportions of eggs are indicated at the top of each bar. Columns with asterisks within stages of meiosis are significantly different $(P<0.001)$.

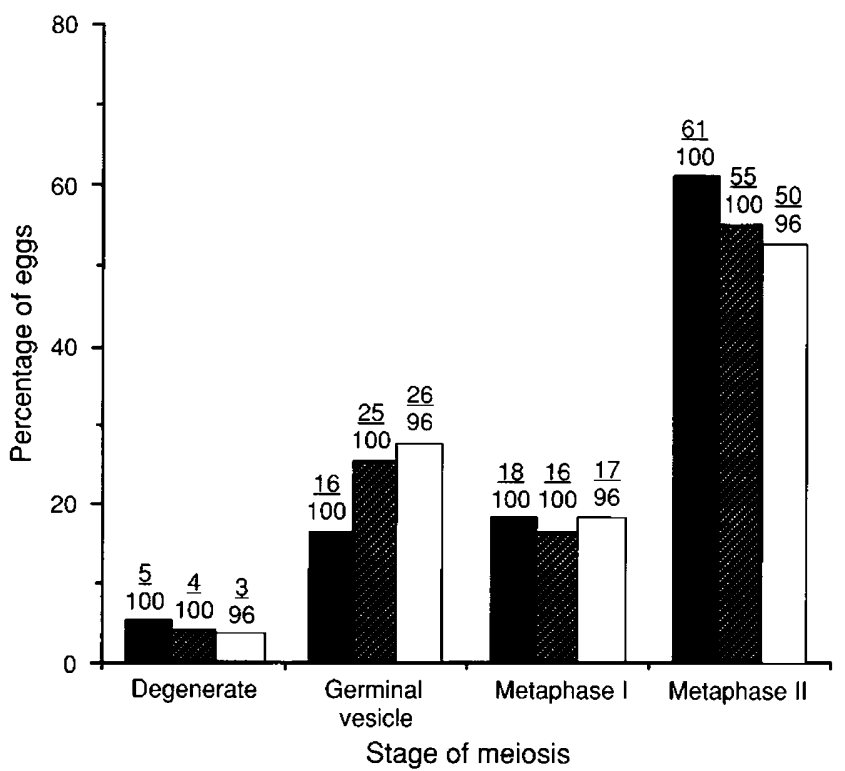

Fig. 4. Meiotic status of eggs cultured in the presence of gonadotrophins $\mathrm{LH}+\mathrm{FSH}$, $(\mathbb{E})$ gonadotrophins + oestradiol, or with ( $\square$ ) oestradiol alone. Numbers and proportions of eggs are indicated at the top of each bar. There were no differences among columns within stages of meiosis $(P>0.05)$.

promoted both egg maturation and fertilization in vitro. The gonadotrophins and oestradiol appeared beneficial, but the impact of progesterone was unclear. In the absence of supplemental hormones, cat eggs achieved nuclear maturation and could fertilize and cleave, but at a highly compromised rate. Fourth, the overall incidence of IVF and two-cell embryo production was relatively low in cat eggs matured for $52 \mathrm{~h}$ in vitro and then co-cultured with spermatozoa in vitro. Whereas $60-80 \%$ of eggs matured in vivo routinely form two-cells after insemination (Donoghue et al., 1992; Johnston et al., 1991b), only about $25 \%$ of in vitro matured eggs cleaved in this maturation protocol.

The data indicated a clear inhibitory role of FCS on cat egg maturation, a finding that generally contrasted to results from most commonly studied species (Thibault, 1977; Schroeder and Eppig, 1984; Leibfried-Rutledge et al, 1987; Vanderhyden and Armstrong, 1989; Trounson et al., 1994). Inhibition of nuclear maturation by FCS was consistent with other findings from this laboratory, in which a single FCS source was used on cat eggs (Johnston et al., 1993). That investigation focused upon the impact of different culture media on antral oocyte maturation in vitro. Supplementing MEM (one of the test media) with FCS resulted in only $9.6 \%$ of eggs achieving maturation, compared with $46.7 \%$ for BSA. Occasionally, reports involving other species suggest a conflicting or equivocal role for FCS. For example, two studies comparing FCS with oestrus cow serum for maturing cow eggs yielded maturation rates of about $60 \%$ for both treatments (Fukui and Ono, 1989; Sanbuissho and Threlfall, 1990); however, in another study in cows, higher egg maturation $(\geq 90 \%)$ was achieved using four different sources of cow serum compared with FCS $(62.9 \%$ ) (Younis et al., 1989). Using rat eggs, Vanderhyden and Armstrong (1989) reported that 10\% FCS produces the lowest maturation rate of five serum sources (rat, goat, pig, human and FCS).

Although serum factors can promote egg maturation in vitro, there are species specificities, and, in cats, it is probable that FCS contains inhibitory elements. The benefits of serum to meiotic maturation in vitro have been linked to its ability to maintain healthy granulosa cells that interact with egg cytoplasm through gap junctions (Downs, 1993). It has been speculated that this two-way interaction allows the introduction of high concentrations of known meiotic inhibitors such as cAMP (Dekel and Beers, 1978; Downs, 1993). It is possible that the serum effects observed in this experiment were associated with cumulus cell-egg cytoplasm interaction. However, these results do not support the theory of spontaneous resumption of meiosis following breakage of gap junctions between granulosa cells and the egg cytoplasm (Dekel and Beers, 1978). Although not quantified, cat cumulus-oocyte complexes matured in FCS for $52 \mathrm{~h}$ clearly expressed more cumulus cell expansion and were more mucified than were eggs matured in BSA or PVA supplemented cultures. It is possible that FCS contains a known or as yet unidentified meiotic inhibitor that exerts an influence independently of cumulus cells. This theory is supported by the observed partial elimination of meiotic inhibition by dialysing FCS. All three treatments (complete, dialysed and recombined serum) supported granulosa cell mucification to the same extent.

The role of reproductive hormones, particularly steroids, in promoting egg maturation in vitro is somewhat ambiguous. The situation in cats appears similar to that in rats, sheep, mice and cows (Moor and Trounson, 1977; Dekel and Beers, 1978; Freter and Shultz, 1984; Zuelke and Brackett, 1990), in that exogenous gonadotrophins in the presence of oestrogen stimulate egg meiotic maturation in vitro. $\mathrm{FSH}$ apparently promotes maturation by regulating CAMP concentrations (Salustri et al., 
1985) associated with enhancing cumulus cell expansion. It has been suggested that FSH stimulates the production of a maturation-promoting factor through a cAMP-dependent process, and that FSH becomes stimulatory when a diminishing threshold cAMP concentration is reached (Downs and Eppig, 1985; Downs et al., 1988; Downs, 1993). LH appears linked to a cAMP-dependent reduction in a meiosis inhibiting factor associated with cumulus cells (Freter and Shultz, 1984), a theory not directly supported by this study. Oestradiol supplements may (Younis et al., 1989) or may not (Fukui, 1989) influence egg maturation in vitro by influencing gap junctions between cumulus cells and the oocyte. In cats, it was important that oestrogen provided similar maturational support to gonadotrophins at $24 \mathrm{~h}$, re-affirming the importance of this hormone. Batten et al. (1989) suggested that progesterone acts synergistically with cAMP to inhibit germinal vesicle breakdown in mouse eggs and is associated with cytoplasmic maturation (Thibault, 1977). There was an equivocal effect of supplemental progesterone in cats and no benefit to egg maturation in vitro.

Sperm-egg interaction in cats occurs readily, and many factors that perturb IVF in other species are rather innocuous in cats (Wildt, 1990; Johnston et al., 1991a, b). For example, varying culture medium, temperature and gas atmosphere have little effect, and cat spermatozoa and eggs readily bind and form cleaved embryos in vitro (Johnston et al, 1991b, c). Eggs recovered from ovarian antral follicles of gonadotrophinprimed cats usually have not achieved metaphase II by the time of egg aspiration (Byers et al, 1994); none the less, this immaturity at recovery has no effect on the ability of conspecific spermatozoa to bind, penetrate and induce embryo cleavage within hours of co-culture. In addition, feline oocytes have been successfully recovered and fertilized after prolonged ovarian storage (up to $30 \mathrm{~h}$ ) in cold $\left(4^{\circ} \mathrm{C}\right)$ saline (Johnston et al, 1989, 1991a). Although this IVM/IVF system appears relatively resistant to an array of conventional variables, the present study indicated that supplemental protein and hormones were important for enhancing in vitro maturation, and that gonadotrophins and oestradiol promoted fertilization in culture. BSA appeared superior to FCS for increasing maturation. However, when $\mathrm{FSH}+\mathrm{LH}+$ oestradiol were present in the culture medium, a higher percentage of the FCS-matured eggs fertilized and cleaved, suggesting that FCS contributed factors important to early embryo development. Although not measured, FCS may have improved fertilization by inhibiting zona pellucida hardening. However, this enhancement was probably due to the ability of FCS-treated egg cytoplasm to support pronuclear development after a prolonged IVM interval of $52 \mathrm{~h}$.

In most species studied to date (sheep, Moor and Trounson, 1977; rats, Fukushima and Fukui, 1985; mice, Downs et al., 1986; cows, Zhang and Armstrong, 1989; Sanbuissho and Threlfall, 1990; Saeki et al., 1991; pigs, Mattioli et al., 1988; and red deer, Fukui et al., 1991), supplementing culture medium with gonadotrophins alone or in combination with steroids enhances IVF of IVM eggs. Cats appeared to benefit from such an approach, as cleavage rates were enhanced twofold when protein supplementation, with gonadotrophins alone or in combination with oestradiol, was added to culture medium. It was predicted that exposure of eggs to progesterone may adversely affect fertilization. This prediction was made on the basis of a parallel study in which eggs matured in vivo were recovered from gonadotrophin-primed cats with ovaries containing only preovulatory follicles or follicles and freshly formed corpora haemorrhagica (Roth et al., 1993). Females with corpora haemorrhagica had ovulated a portion of their follicular cohort prematurely and were in a progestin-secreting (luteal) phase. Upon insemination, only $50.4 \%$ of eggs from the prematurely ovulating cats cleaved, compared with $68.2 \%$ of eggs from females with ovaries containing only preovulatory follicles $(P<0.05)$. This compromising effect also appeared to occur in the present study, as exposing immature eggs to progesterone during IVM/IVF culture reduced subsequent fertilization and cleavage by at least half.

The IVF cleavage success observed here was comparable to the findings of Johnston et al. (1989), in which immature cat eggs were cultured and inseminated in modified Kreb's Ringer bicarbonate. The relatively low overall cleavage rate $(26 \%)$ recorded by Johnston et al. (1989) and in this study for eggs supplemented with BSA or FCS and gonadotrophins with or without steroids is in marked contrast to IVF success using eggs matured in vivo. In general, between $60 \%$ and $80 \%$ of eggs recovered from ovarian follicles of gonadotrophin-treated cats form cleaved embryos within $30 \mathrm{~h}$ of insemination in vitro (Goodrowe et al., 1988; Johnston et al., 1991b, c; Donoghue et al., 1992), and $80 \%$ of these readily develop in vitro to morula-stage embryos (Johnston et al, 1991c; Howard et al., 1993). Furthermore, the biological competence of these embryos has been demonstrated in transfer trials (Goodrowe et al., 1988). Certainly, there is a profound difference in fertilization and development efficiency using eggs matured in vivo compared with eggs matured in vitro. Although (i) culture medium appears to exert a modest effect (Johnston et al., 1993) and (ii) the presence of supplemental gonadotrophins and oestradiol has been found to be important, the definitive factors responsible for enhancing IVM/IVF of immature antral cat eggs remain to be identified.

Johnston et al. (1989) suggest that the fertilization success of cat eggs matured in vitro appears highly time-dependent; inseminating too early or late markedly reduces the incidence of IVF, suggesting perhaps a narrow window of egg viability. Preliminary studies suggest that cat eggs matured with BSA for $24 \mathrm{~h}$ readily undergo fertilization in vitro. Of 110 eggs matured and co-cultured with spermatozoa for $18 \mathrm{~h}, 65 \%$ matured, $89 \%$ of mature eggs fertilized and cleaved, and $89 \%$ of the cleaved eggs developed to at least the morula stage (T. C. Wood and D. E. Wildt, unpublished observations). These results are comparable with the development of eggs matured in vivo and fertilized and cultured in vitro (Goodrowe et al., 1988; Johnston et al., 1991b, c; Donoghue ef al., 1992; Roth et al., 1994). Therefore, current studies emphasize the temporal dynamics of maturation onset and optimal insemination time. It is also predicted that cat ovaries contain eggs of vastly different quality and developmental status. Follicle or egg developmental atresia has not been studied extensively in induced ovulators (such as cats), in which regulatory controls to egg maturation and viability involve other complex factors like multiple copulatory stimuli (Wildt, 1990, 1991). The impact of this little understood phenomenon and the difficulty of grossly quantifying egg quality because of a dark, lipid-rich cytoplasm 
(Guraya, 1965; Byers et al., 1994) suggest that more effort must be directed at measuring the quality of cat eggs at harvest and before selection for IVM culture. For this reason, histological characterization studies are in progress, interrelating ovarian follicle size, gross egg morphometry and appearance, and subsequent ability to develop in vitro.

The authors acknowledge the National Hormone and Pituitary Program for supplying gonadotrophins, J. J. Miller (George Mason University) for statistical assistance and the Petworth and Friendship Animal Clinics of Washington DC for supplying ovaries. Special thanks go to B. Pukazhenthi for dialysing the serum. This research was supported by grants from the Smithsonian Institution Scholarly Studies Program, Friends of the National Zoo (FONZ) and a George Mason University Graduate Fellowship (to T. C. Wood).

\section{References}

Batten BA, Roh SI and Kim MH (1989) Effects of progesterone and a progesterone antagonist (RU486) on germinal vesicle breakdown in the mouse Anatomical Record 223 387-392

Brackett BG, Younis AI and Fayrer-Hosken RA (1989) Enhanced viability after in vitro fertilization of bovine oocytes matured in vitro with high concentrations of luteinizing hormone Fertility and Sterility 52 319-324

Byers AP, Donoghue AM, Roth TL and Wildt DE (1994) Oocyte nuclear maturation at the time of oocyte aspiration is independent of in vitro fertilization potential in the domestic cat Journal of Experimental Zoology 270 399-404

Dekel N and Beers WH (1978) Rat oocyte maturation in vitro: relief of cyclic AMP inhibition by gonadotrophins Proceedings of the National Academy of Sciences USA 75 4369-4373

Donoghue AM, Johnston LA, Munson L, Brown JL and Wildt DE (1992) Influence of gonadotrophin treatment interval on follicular maturation, in vitro fertilization, circulating steroid concentrations, and subsequent luteal function in the domestic cat Biology of Reproduction 46 972-980

Downs SM (1993) Factors affecting the resumption of meiotic maturation in mammalian oocytes Theriogenology 39 65-79

Downs SM and Eppig JJ (1985) A follicular fluid component prevents gonadotrophin reversal of cyclic adenosine monophosphate-dependent meiotic arrest in murine oocytes Gamete Research 11 83-97

Downs SM, Schroeder AC and Eppig JJ (1986) Serum maintains the fertilizability of mouse oocytes matured in vitro by preventing the hardening of the zona pellucida Gamete Research 15 115-122

Downs SM, Daniel SAJ and Eppig JJ (1988) Induction of maturation in cumulus cell-enclosed mouse oocytes by follicle-stimulating hormone and epidermal growth factor: evidence for a positive stimulus of somatic cell origin Journal of Experimental Zoology 245 86-96

Dunn OJ (1961) Multiple comparisons among means Journal of the American Statistical Association $56 \quad 52-64$

Eppig JJ (1991) Mammalian oocyte development in vivo and in vitro. In Elements of Mammalian Fertilization Vol. 1 Basic Concepts pp 57-76 Ed. PM Wasserman. CRC Press, Boca Raton, FL

Freter RR and Schultz RM (1984) Regulation of murine oocyte meiosis: evidence for a gonadotrophin-induced, cAMP-dependent reduction in a maturation inhibitor Journal of Cell Biology 98 1119-1128

Fukui Y (1989) Effects of sera and steroid hormones on development of bovine oocytes matured and fertilized in vitro and co-cultured with bovine oviduct epithelial cells Journal of Animal Science 67 1318-1323

Fukui $Y$ and Ono $H$ (1989) Effects of sera, hormones and granulosa cells added to culture medium for in vitro maturation, fertilization, cleavage and development of bovine oocytes Journal of Reproduction and Fertility 86 501-506

Fukui Y, McCowan LT, James RW, Asher GW and Tervit HR (1991) Effects of .culture duration and time of gonadotrophin addition on in vitro maturation and fertilization of red deer (Cerous elaphus) oocytes Theriogenology 35 $499-512$

Fukushima M and Fukui $Y$ (1985) Effects of gonadotrophins and steroids on the fertilizability of extracellular bovine oocytes cultured in vitro Animal Reproduction Science 9 323-332
Goodrowe KL, Wall RJ, O'Brien SJ, Schmidt PM and Wildt DE (1988) Developmental competence of domestic cat follicular oocytes after fertilization in vitro Biology of Reproduction 39 355-372

Goodrowe KL, Hay M, and King WA (1991) Nuclear maturation of domestic cat ovarian oocytes in vitro Biology of Reproduction 45 460-470

Guraya SS (1965) A histochemical analysis of lipid yolk deposition in the oocytes of cat and dog Journal of Experimental Zoology 160 123-136

Howard JG, Bush M and Wildt DE (1986) Semen collection, analysis and cryopreservation in nondomestic mammals. In Current Therapy in Theriogenology pp 1047-1053 Ed. D Morrow. WB Saunders Co, Philadelphia

Howard JG, Donoghue AM, Johnston LA and Wildt DE (1993) Zona pellucida filtration of structurally abnormal spermatozoa and reduced fertilization in teratospermic cats Biology of Reproduction 49 131-139

Johnston LA, O'Brien SJ and Wildt DE (1989) In vitro maturation and fertilization of domestic cat follicular oocytes Gamete Research 24 434-456

Johnston LA, Donoghue AM, O'Brien SJ and Wildt DE (1991a) "Rescue" and maturation in vitro of follicular oocytes of nondomestic felid species Biology of Reproduction 45 898-906

Johnston LA, Donoghue AM, O'Brien SJ and Wildt DE (1991b) Culture medium and protein source influence in vitro fertilization and embryo development in the domestic cat journal of Experimental Zoology 257 350-359

Johnston LA, Donoghue AM, O'Brien SJ and Wildt DE (1991c) Influence of temperature and gas atmosphere on in vitro fertilization and embryo development in the domestic cat Journal of Reproduction and Fertility 92 377-382

Johnston LA, Donoghue AM, O'Brien SJ and Wildt DE (1993) Influence of culture medium and protein supplementation on in vitro oocyte maturation and fertilization in the domestic cat Theriogenology 80 829-839

Karlach V (1987) The effect of FSH, LH, $\beta$-oestradiol, and progesterone on cytoplasmic maturation of bovine follicular oocytes in vitro Folia Biologica (Prague) 33 258-265

Leibfried-Rutledge ML, Critser ES and First NL (1986) Effects of fetal calf serum and bovine serum albumin on in vitro maturation and fertilization of bovine and hamster cumulus-oocyte complexes Biology of Reproduction 35 $850-857$

Leibfried-Rutledge ML, Critser ES, Eyestone WH, Northey DL and First NL (1987) Development potential of bovine oocytes matured in vitro or in vivo Biology of Reproduction 36 376-383

Mattioli M, Galeati G, Bacci ML and Seren E (1988) Follicular factors influence oocyte fertilizability by modulating the intercellular co-operation between cumulus cells and oocytes Gamete Research 21 223-232

Moor RM and Trounson AO (1977) Hormonal and follicular factors affecting maturation of sheep oocytes in vitro and their subsequent developmental capacity Journal of Reproduction and Fertility 49 101-109

Moor RM, Polge C and Willadsen SM (1980) Effects of follicular steroids on the maturation of mammalian oocytes Joumal of Embryology and Experimental Morphology 56 319-335

Ocampo MB, Ocampo LC, Ryu IS, Mori T, Ueda J and Kanagawa H (1993) Effects of culture time, ovarian activity, cumulus cells and sera on the nuclear and cytoplasmic maturation of pig oocytes in vitro Animal Reproduction Science 34 135-146

Roth TL, Donoghue AM, Byers AP, Munson L and Wildt DE (1993) Influence of oviductal cell monolayer-co-culture in the presence of corpora hemorrhagica at the time of oocyte aspiration on gamete interaction in vitro in the domestic cat Journal of Assisted Reproduction and Genetics 10 $523-529$

Roth TL, Swanson WF and Wildt DE (1994) Developmental competence of domestic cat embryos fertilized in vivo versus in vitro Biology of Reproduction 51 441-451

Saeki K, Hoshi M, Leibfried-Rutledge ML and First NL (1991) In vitro fertilization and development of bovine oocytes matured in serum-free medium Biology of Reproduction 44 256-260

Salustri A, Petrungaro S, DeFelici M, Conti M and Siracusa G (1985) Effect of follicle-stimulating hormone on cyclic adenosine monophosphate level and on meiotic maturation in mouse cumulus cell-enclosed oocytes cultured in vitro Biology of Reproduction 33 797-802

Sanbuissho A and Threlfall WR (1990) The influence of serum and gonadotrophins on in vitro maturation and fertilization of bovine oocytes Theriogenology 34 341-348

Schroeder AC and Eppig J (1984) The developmental capacity of mouse oocytes that matured spontaneously is normal Developmental Biology 102 493-497 
Schroeder AC, Schultz RM, Kopf GS, Taylor FR, Becker RB and Eppig J (1990) Fetuin inhibits zona pellucida hardening and conversion of $\mathrm{ZP} 2$ to $\mathrm{ZP} 2_{\mathrm{f}}$ during spontaneous mouse oocyte maturation in vitro in the absence of serum Biology of Reproduction 43 891-897

Schultz RM (1991) Meiotic maturation of mammalian oocytes. In Elements of Mammalian Fertilization Volume 1 Basic Concepts pp 77-194 Ed. PM Wasserman. CRC Press, Boca Raton, FL

Sirard MA, Leibfried-Rutledge ML, Parrish JJ, Ware CM and First NL (1988) The culture of bovine oocytes to obtain developmentally competent embryos Biology of Reproduction 39 546-552

Sojka NJ, Jennings LL and Hamner CE (1970) Artificial insemination in the cat (Felis catus l.) Laboratory Animal Care 20 198-204

Thibault C (1977) Are follicular maturation and oocyte maturation independent processes? Journal of Reproduction and Fertility 51 1-15

Thibault C, Szollosi D and Gerard M (1987) Mammalian oocyte maturation Reproduction, Nutrition and Development 27 865-896

Trounson A, Pushett D, Maclellan LJ, Lewis I and Gardner DK (1994) Current status of IVM/IVF and embryo culture in humans and farm animals Theriogenology 41 57-66
Vanderhyden BC and Armstrong DT (1989) Role of cumulus cells and serum on in vitro maturation, fertilization and subsequent development of rat oocytes Biology of Reproduction $\mathbf{4 0} 720-728$

Wildt DE (1990) Potential applications of IVF technology for species conservation. In Fertilization in Mammals pp 349-364 Eds BD Bavister J Cummins and ERS Roldan. Serono Symposium, USA, Norwell, Massachusetts

Wildt DE (1991) Fertilization in cats. In A Comparative Overview of Mammalian Fertilization pp 299-328 Eds BS Dunbar and M O'Rand. Plenum Publishing Corporation, Philadelphia

Younis Al, Brackett BG and Fayrer-Hosken RA (1989) Influence of serum and hormones on bovine oocyte maturation and fertilization in vitro Gamete Research 23 189-201

Zhang X and Armstrong DT (1989) Effects of follicle-stimulating hormone and ovarian steroids during in vitro meiotic maturation on fertilization of rat oocytes Gamete Research 23 267-277

Zuelke KA and Brackett BG (1990) Luteinizing hormone-enhanced in vitro maturation of bovine oocytes with and without protein supplementation Biology of Reproduction 43 784-787 